\title{
Mitral valve bypass: Another extra-anatomic solution for another tiger territory?
}

\author{
Sameh M. Said, MBBCh, MD, FACS
}

\author{
From the Department of Cardiovascular Surgery, Mayo Clinic, Rochester, Minn. \\ Disclosures: Author has nothing to disclose with regard to commercial support. \\ Received for publication Oct 3, 2018; accepted for publication Oct 4, 2018. \\ Address for reprints: Sameh M. Said, MBBCh, MD, FACS, Associate Professor of Surgery, Division of Pediatric \\ Cardiac Surgery, Masonic Children's Hospital, University of Minnesota, 2450 Riverside Ave S, East Building, \\ MB539, Minneapolis, MN 55454 (E-mail: ssaid@umn.edu). \\ J Thorac Cardiovasc Surg 2019;157:e147-8 \\ $0022-5223 / \$ 36.00$ \\ Copyright (C) 2018 Published by Elsevier Inc. on behalf of The American Association for Thoracic Surgery \\ https://doi.org/10.1016/j.jtcvs.2018.10.008
}

Calcified mitral annulus has been the cardiac surgeon's nightmare for a long time. Several surgical strategies have been proposed to replace the mitral valve (MV) in the presence of extensive annular calcifications (MAC). This starts from standard radical annular decalcifications (Figure 1), which will require reconstruction of the left atrioventricular junction followed by MV replacement. This-despite being the ideal solution in my mind-obviously mandates expertise and time and might not be a safe option in some patients with advanced age and multiple comorbidities. Other alternatives such as the "just do it" approach, although common, is not a good option because of the risk of periprosthetic regurgitation and circumflex coronary artery injury from passing the sutures through or deeper to the MAC. Recently, we had experience with MV bypass using a valved conduit from the left atrium to the left ventricular apex. ${ }^{1}$ The inflow of the conduit can be from the left atrial appendage or the left atriotomy itself. The advantages of using the left atrial appendage are the shorter length of the conduit and the ability to place the conduit completely away from the midline and more into the left chest.

In the current case by López-Rodríguez and colleagues, ${ }^{2}$ the authors describe this technique in a 66-year-old patient with previous aortic valve replacement. The authors used an On-X conform mitral prosthesis, which was sewn to the left ventricular apex and a 30-mm graft, which was connected to the left atrial appendage. The procedure was successful in improving the patient's symptoms.

However, our experience taught us few important tips:

1. The valve should be placed as close to the left ventricular apex as possible to avoid having a long blind segment before the outflow point;

2. The conduit needs to be as short as possible;

3. It is difficult to visualize the conduit using standard echocardiographic images and cross-sectional images such as computed tomography scan are usually required if any problem is suspected;

4. It is important to select the correct patient: there is a certain group of patients who are challenging such as

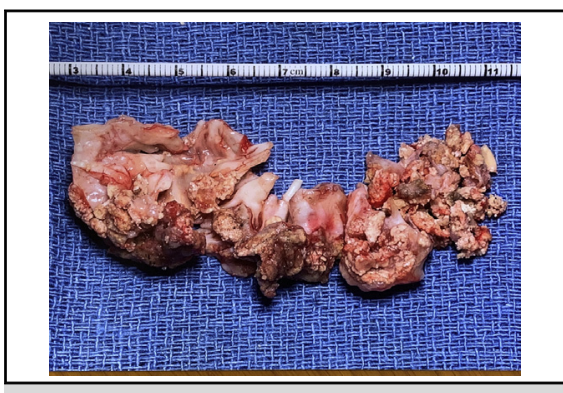

Calcifications removed from the mitral annulus.

Central Message

Left atrial to left ventricular valved conduit can be a useful alternative to mitral valve replacement in the presence of dense annular calcifications in properly selected patients.

See Article page e143.

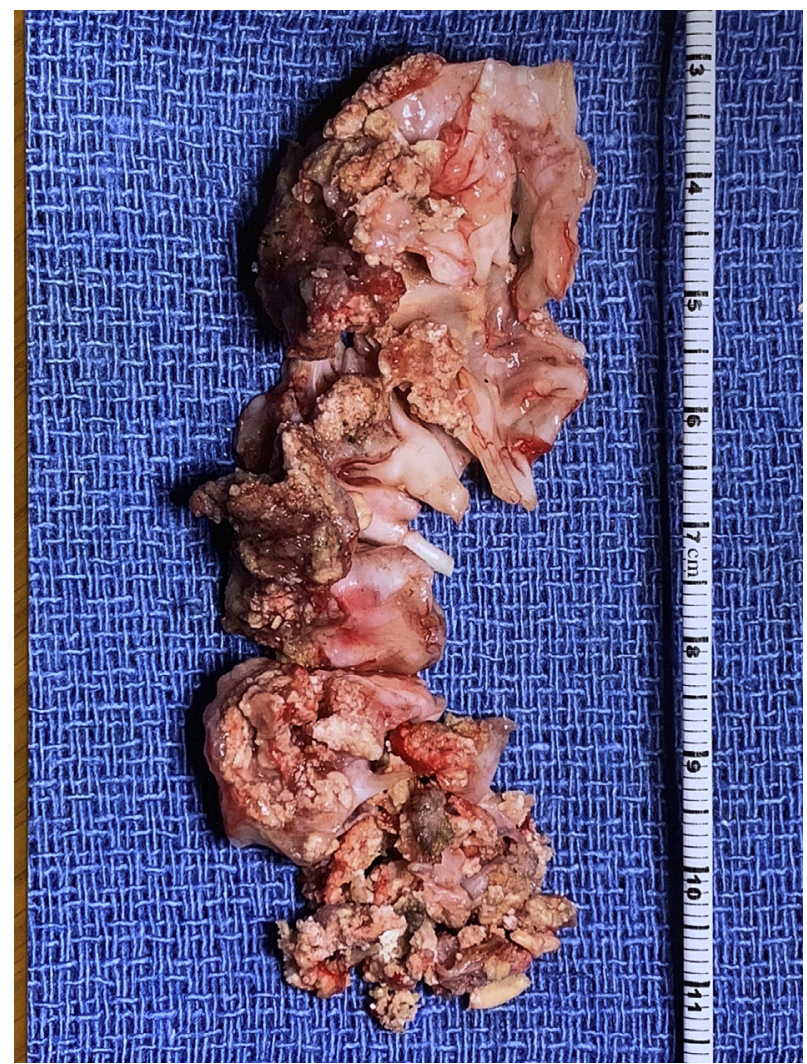

FIGURE 1. Calcifications removed from the mitral annulus. 
those with previous chest radiation and patients with hypertrophic cardiomyopathy;

5. Cases with concomitant MV regurgitation represent a problem because the extracardiac conduit will not be efficient in these cases and it will behave as if there is a significant periprosthetic leak. Attempts at repairing the MV in these cases are usually unsuccessful in eliminating the regurgitation because of the extensive calcifications; therefore, the ideal patient for this procedure is the one with isolated MV stenosis.

In conclusion, MV bypass with a valved conduit can be a good alternative in the properly selected patient to avoid dealing with dense MAC in older frail patients or those with multiple comorbidities. Currently, our preferred technique in these cases is the direct transatrial implantation of modified Edwards Sapien bioprosthesis
(Edwards Lifesciences Corp, Irvine, Calif), which is another useful technique that should be included in the cardiac surgeon's armamentarium for these challenging scenarios. ${ }^{3,4}$

\section{References}

1. Said SM, Schaff HV. An alternate approach to valve replacement in patients with mitral stenosis and severely calcified annulus. J Thorac Cardiovasc Surg. 2014; 147:e76-8.

2. López-Rodríguez FJ, García ME, Santos JM, Pérez MB. Left atrial to left ventricular valved conduit for a calcified mitral annulus and ascending aorta. J Thorac Cardiovasc Surg. 2019;157:e143-5.

3. El Sabbagh A, Eleid MF, Foley TA, Al-Hijji MA, Daly RC, Rihal CS, et al. Direct transatrial implantation of balloon-expandable valve for mitral stenosis with severe annular calcifications: early experience and lessons learned. Eur J Cardiothorac Surg. 2018;53:162-9.

4. Russell HM, Guerrero ME, Salinger MH, Manzuk MA, Pursnani AK, Wang D, et al. Open atrial transcatheter mitral valve replacement in patients with mitral annular calcification. J Am Coll Cardiol. 2018;72:1437-48. 